\title{
The Effect of $\mathrm{CuO} / \mathrm{CeO}_{2}$ Preparation Methods on the $\mathrm{HCN}$ Catalytic Removal Efficiency
}

\author{
Yulin Yang ${ }^{1}$, Zhihao $\mathrm{Yi}^{1}$, Jie Sun ${ }^{\square *}$, Jigang $\mathrm{Li}^{\square}$, Tian Zhou ${ }^{\square}$, Shouping Wei ${ }^{\natural}$. \\ ${ }^{1}$ Department of Chemistry Defense, Institute of NBC Defense, Beijing 102205, China.
}

\begin{abstract}
In this paper, the porous $\mathrm{CeO}_{2}$ flowerlike spheres support and a series of $\mathrm{CuO} / \mathrm{CeO}$ prepared by different methods were synthesized. The SEM, XRD, BET, $\mathrm{H}_{2}-\mathrm{TPR}$ and FT-IR characterization were conducted to probe the physicochemical properties of the samples. To evaluate the HCN catalytic removal efficiency over the prepared samples, the breakthrough time of HCN over different samples were investigated. The results implied the $\mathrm{CuO} / \mathrm{CeO}_{2}$ prepared by precipitation method (donated as $\mathrm{Ce}-5$ ) showed highest catalytic activity, the breakthrough time of which was more than $70 \mathrm{~min}$ at $30^{\circ} \mathrm{C}$. It was proved the dispersion of $\mathrm{CuO}$ phase on the support, the redox properties and the interaction between $\mathrm{CuO}$ and $\mathrm{CeO}_{2}$ support over $\mathrm{CuO} / \mathrm{CeO}_{2}$ played an important role in the $\mathrm{HCN}$ catalytic removal process. FT-IR analysis demonstrated the $\mathrm{CuCN}$ was generated due to the chemisorption of $\mathrm{CuO}$ and $\mathrm{HCN}$.
\end{abstract}

\section{Introduction}

Hydrogen cyanide (HCN), which is colorless and poisonous with boiling point of $26{ }^{\circ} \mathrm{C}$, comes from various sources, including the combustion of fossil, selective reduction of NOx, polymer pyrolysis and yellow phosphorus production [1-3]. HCN can cause disability and even death by entering the human body through skin penetration and respiratory inhalation and reacting with $\mathrm{Fe} 3+$ in the cell to prevent cell respiration [4-6]. Due to the high vapor pressure and volatility and the low molecular weight of $\mathrm{HCN}$, traditional protective materials are difficult to achieve ideal removal efficiency. Therefore, the development of new material which could achieve deep purification of $\mathrm{HCN}$ has caused intensive interests.

To our best knowledge, there are main four methods for the removal of $\mathrm{HCN}$, including absorption, combustion, catalytic hydrolysis and catalytic oxidation [7]. Ning et al [8] prepared metal $(\mathrm{Cu}, \mathrm{Co}, \mathrm{Zn})$ loaded ZSM-5 zeolite materials and investigated its removal ability toward $\mathrm{HCN}$, when loaded with $\mathrm{Cu}$, the $\mathrm{HCN}$ breakthrough capacity was enhanced significantly. Krocher [9] studied the HCN removal performance over various catalysts. $\mathrm{TiO}_{2}$ anatase exhibited a high $\mathrm{HCN}$ hydrolysis activity and could attain $90 \%$ conversion at $400{ }^{\circ} \mathrm{C}$. Wang [10] reported that $\mathrm{La}_{1} \mathrm{Cuy}_{9} / \mathrm{TiO}_{2}$ showed the best performance for $\mathrm{HCN}$ removal, the removal rate of $100 \mathrm{ppm} \mathrm{HCN}$ over which could achieve $100 \%$. The addition of La improved the reduction performance of the catalyst and the number of acid sites, which could accelerate the reduction of the hydrolysis by-product $\mathrm{NH}_{3}$ by $\mathrm{NH}_{3}-\mathrm{SCR}$ reaction. $\mathrm{Ma}$ [11] reported the DI-20Al-Ti prepared by self-assembly method can achieve 100\% HCN conversion and 90\% CO selectivity at $250^{\circ} \mathrm{C}$, which was attributed to its large specific surface area, high dispersion of micropore, and a mass of alkaline sites. Hu [12] prepared Fe-Cu/ HZSM-5 catalytic material by sol-gel method, the $\mathrm{HCN}$ conversion and $\mathrm{N}_{2}$ selectivity over which were $100 \%$ and $80 \%$ at $250^{\circ} \mathrm{C}$. The synergetic of bio-metal of $\mathrm{Fe}-\mathrm{Cu} / \mathrm{HZSM}-5$ enhance the reduction performance toward $\mathrm{HCN}$ due to the increase of dispersion of metal oxide compared with load single metal.

From above analysis, the catalytic materials reported need higher reaction temperature $\left(>200^{\circ} \mathrm{C}\right)$ to achieve deep purification of $\mathrm{HCN}$, which cost a lot of energy. Besides, these samples could not meet the requirements of gas mask which is usually employed in the temperature region of $-20 \sim 30^{\circ} \mathrm{C}$. It is urgent to develop a material to show high catalytic activity toward HCN at lower temperature $\left(<30^{\circ} \mathrm{C}\right)$ and could be employed in the gas mask.

$\mathrm{CeO}_{2}$ possesses the property of $n$-type semiconductor. When loaded with metal oxide, $\mathrm{CeO}_{2}$ can significantly improve catalytic activity, reaction selectivity and stability due to the synergy between metal oxide and $\mathrm{CeO}_{2}$ support [13-14]. Compared with the traditional $\mathrm{CeO}_{2}$, the porous $\mathrm{CeO}_{2}$ flowerlike spheres prepared by hydrothermal method was covered with more oxygen vacancies and $\mathrm{Ce}^{3+}$ and the storage capacity of oxygen was greatly improved. Sun [15] prepared $\mathrm{CuO} / \mathrm{CeO}_{2}(15 \mathrm{wt} . \%)$ and investigated its catalytic performance toward ethanol reforming. The selectively of $\mathrm{H}_{2}$ was $74.1 \%$, and the maximum conversion of ethanol was $88.3 \%$, while the CO were less than $4 \%$ at whole reaction temperature range. Tan reported

The first author: Yulin Yang ${ }^{1}$ Tel: 18839122971; E-mail: 771467738@qq.com.

Zhihao Yi ${ }^{1}$ Tel: 18510358993; E-mail: 358032761@qq.com.

*Corresponding author. Tel: 8610-66756282; E-mail: magnsun@mail.tsinghua.edu.cn 
the catalytic activity of $\mathrm{CeO}_{2}$ loaded with metal oxide $\left(\mathrm{CuO}, \mathrm{Fe}_{2} \mathrm{O}_{3}, \mathrm{La}_{2} \mathrm{O}_{3}\right)$ toward styrene conversion. The results indicated that $\mathrm{CuO} / \mathrm{CeO}_{2}$ could achieve higher styrene conversion than other samples due to its more active oxygen species on the surface [16]. Although the $\mathrm{CuO} / \mathrm{CeO}_{2}$ exhibited excellent catalytic performance toward styrene and ethanol, there was hardly reports for the HCN removal. Based on the above analysis, we prepared porous $\mathrm{CeO}_{2}$ flowerlike spheres and a series of $\mathrm{CuO} / \mathrm{CeO}_{2}$ with fixed mass ratio to investigate the impact of different preparation methods on $\mathrm{HCN}$ removal at room temperature, which provide better preparation method of catalytic material.

In this work, the porous $\mathrm{CeO}_{2}$ flowerlike spheres loaded with $\mathrm{CuO}$ species were prepared and were applied for $\mathrm{HCN}$ removal at $30{ }^{\circ} \mathrm{C}$. The physicochemical properties were probed by means of XRD, BET, SEM, $\mathrm{H}_{2}-$ TPR and FT-IR analysis, and the effect of preparation methods on samples' catalytic activity were investigated.

\section{2. preparation of catalysts}

\section{1.preparation of support- $\mathrm{CeO}_{2}$}

In the typical experiment, C6H12O6 $\mathrm{H} 2 \mathrm{O}$ (3.5 g), acrylamide (3.5 g), $\mathrm{Ce}(\mathrm{NO} 3) \cdot 3 \mathrm{H} 2 \mathrm{O}$ (7 g) were dissolved into $180 \mathrm{ml}$ deionized water with magnetic stirring. The ammonia solution ( $25 \mathrm{wt} . \%$ ) was added into the solution to adjust the $\mathrm{pH}$ value. When the solution became suspension, the color of it became brown during the adding. the suspension was stirred for $3 \mathrm{~h}$. After that, the suspension was transferred into the Teflon-lined autoclave (200 ml), which was sealed and kept at $180{ }^{\circ} \mathrm{C}$ for $72 \mathrm{~h}$ in the electric oven. After cooled to the room temperature. the obtained solution was centrifugally washed by deionized water and alcohol. The porous $\mathrm{CeO} 2$ flowerlike spheres support could be obtained after the precipitate was dried at $80{ }^{\circ} \mathrm{C}$ for $12 \mathrm{~h}$ and calcinated at $550{ }^{\circ} \mathrm{C}$ for $4 \mathrm{~h}$.

\section{2.the preparation of $\mathrm{CuO} / \mathrm{CeO}_{2}$ catalytic material}

\subsection{1.chemical absorption method}

In the typical experiment, ammonia solution (25 wt.\%) was added into a $50 \mathrm{ml} \mathrm{Cu}(\mathrm{NO} 3) 2$ solution $(1.08 \mathrm{~g}$ $\mathrm{Cu}(\mathrm{NO} 3) 2 \cdot 3 \mathrm{H} 2 \mathrm{O})$ at rate of $1 \mathrm{drop} / \mathrm{s}$ with magnetic stirring to adjust the $\mathrm{pH}$ value of the solution to 9 , then $\mathrm{CeO} 2$ powder $(4 \mathrm{~g})$ was dispersed into the solution, followed by aging for 30 minutes in ice water. After that, deionized water $(200 \mathrm{ml})$ was slowly added into the above solution with stirring. Upon the addition of the deionized water, the solution became murky, and then standed still for $2 \mathrm{~h}$ without stirring. After removing water layer, the precipitate was centrifugally washed with deionized water and alcohol until the upper liquid was colorless, and then dried at $80{ }^{\circ} \mathrm{C}$ for $12 \mathrm{~h}$. The catalytic material donated as Ce- 1 was obtained after calcination at $450{ }^{\circ} \mathrm{C}$ for $4 \mathrm{~h}$.

\subsection{2. $\mathrm{K}_{2} \mathrm{C}_{2} \mathrm{O}_{4}$ impregnation method}

In the typical experiment, $\mathrm{CeO} 2$ powder $(4 \mathrm{~g})$ and $\mathrm{K} 2 \mathrm{C} 2 \mathrm{O} 4$ (1.35 g) was dissolved into deionized water (50 $\mathrm{ml}$ ) with magnetic stirring, which was followed by addition of $20 \mathrm{ml}$ solution of $\mathrm{Cu}(\mathrm{NO} 3) 2(1.08 \mathrm{~g}$ $\mathrm{Cu}(\mathrm{NO} 3) 2 \cdot 3 \mathrm{H} 2 \mathrm{O})$ at the rate of $1 \mathrm{drop} / \mathrm{s}$ with stirring. After titration of the solution of $\mathrm{Cu}(\mathrm{NO} 3) 2$, stirring for 4 $\mathrm{h}$ to get suspension. Then the suspension was washed by deionized water and alcohol until the upper liquid became colorless. The precipitate was dried $80^{\circ} \mathrm{C}$ for $12 \mathrm{~h}$, and then was calcined at $450^{\circ} \mathrm{C}$ for $4 \mathrm{~h}$. The acquired material was donated as $\mathrm{Ce}-2$.

\subsubsection{Equal volume impregnation method}

The $\mathrm{Cu}(\mathrm{NO} 3) 2 \cdot 3 \mathrm{H} 2 \mathrm{O}(1.08 \mathrm{~g})$ was dissolved into deionized water $(50 \mathrm{ml})$, which was followed by addition of $\mathrm{CeO} 2$ powder $(4 \mathrm{~g})$ with magnetic stirring. Then solution was standed still for $24 \mathrm{~h}$. After that, the upper liquid was evaporated, the material got by evaporation was dried at $80^{\circ} \mathrm{C}$ for $12 \mathrm{~h}$. Then the dried was calcined at $450{ }^{\circ} \mathrm{C}$ for $4 \mathrm{~h}$. The catalytic material donated as $\mathrm{Ce}-3$ was obtained after calcination at $450{ }^{\circ} \mathrm{C}$ for $4 \mathrm{~h}$.

\subsubsection{Coprecipitation method}

The $\mathrm{Cu}(\mathrm{NO} 3) 2 \cdot 3 \mathrm{H} 2 \mathrm{O}(1.08 \mathrm{~g})$ and $\mathrm{Ce}(\mathrm{NO} 3) 3 \cdot 6 \mathrm{H} 2 \mathrm{O}$ $(12.6 \mathrm{~g})$ were dissolved into deionized water $(160 \mathrm{ml})$ with magnetic stirring, subsequently adding $\mathrm{C} 6 \mathrm{H} 12 \mathrm{O} 6 \cdot \mathrm{H} 2 \mathrm{O}$ $(6.3 \mathrm{~g})$ and acrylamide $(6.3 \mathrm{~g})$ to the solution. After that, ammonia solution (mass fraction of $25 \%$ ) was injected into the above solution to adjust the $\mathrm{PH}$ value to 10 . This solution mixture was stirred for $3 \mathrm{~h}$ before washed by deionized water and alcohol. The solution was washed until the upper liquid was colorless. Then the precipitate was dried at $80^{\circ} \mathrm{C}$ for $12 \mathrm{~h}$, and then calcined at $450{ }^{\circ} \mathrm{C}$ for $4 \mathrm{~h}$. The obtained catalytic material was donated as Ce4.

\subsubsection{Precipitation method}

The $\mathrm{CeO} 2$ powder $(4 \mathrm{~g})$ was impregnated into deionized water $(40 \mathrm{ml})$ with magnetic stirring, which became the suspension. The $50 \mathrm{ml}$ solution of $\mathrm{Cu}(\mathrm{NO} 3) 2 \cdot 3 \mathrm{H} 2 \mathrm{O}(1.08 \mathrm{~g})$ was added into the suspension at rate of 1 drop every second with stirring. After that, $\mathrm{NaCO} 3$ ( $1 \mathrm{~mol} / \mathrm{L})$ was added to the suspension to make the $\mathrm{pH}$ value to 9 . Then acquired suspension was stirred for $5 \mathrm{~h}$ at room temperature to guarantee the reaction was finished completely, and then standed still for $24 \mathrm{~h}$. The acquired upper liquid was taken out, and the precipitate was washed by deionized water and alcohol till the upper liquid became colorless, and then dried at $80^{\circ} \mathrm{C}$ for $12 \mathrm{~h}$. The Ceria-supported $\mathrm{CuO}$ was obtained by calcination at $450{ }^{\circ} \mathrm{C}$ for $4 \mathrm{~h}$. The catalytic material after calcination was donated as $\mathrm{Ce}-5$. 


\subsection{The active evaluation of catalytic materials}

The catalytic activity tests of the prepared samples toward $\mathrm{HCN}$ were carried out in a quartz tube (with an inner diameter of $5 \mathrm{~mm}$ ) on a fixed bed loaded with $0.25 \mathrm{~g}$ samples. The whole device was self-made which was shown in Figure 1. The experimental processes were as followed: the air purified by the Quadruple Scrubber and HCN with certain flow rate were obtained by setting the Mass Flow Controller, by changing the flow rate of air, the water content could be adjusted via being diverted to the water bubbler, then $130 \mathrm{mg} / \mathrm{m} 3 \mathrm{HCN}$ with 5 vol.\% H2O was introduced into the catalytic material bed. The exhaust gas was absorbed by the $\mathrm{NaOH}$ solution $(1 \mathrm{~mol} / \mathrm{L})$.

The removal performance of all samples toward HCN was carried out at the condition of 20.4 vol.\% O2, 5vol.\% $\mathrm{H} 2 \mathrm{O}$ and $61146 \mathrm{~h}-1$. The concentration of $\mathrm{HCN}(\mathrm{mg} / \mathrm{m} 3)$ at the outlet was detected by Spectrophotometry of isonicotinic acid-pyrazolone solution, the detection limits of which was $0.005 \mathrm{mg} / \mathrm{L}$. The catalytic activity of samples was evaluated by the breakthrough time when the HCN removal rate was lower than $100 \%$. The HCN removal rate at different reaction time was calculated as follows:

$$
Y=\left(1-\frac{C}{C_{0}}\right) * 100 \%
$$

the $\mathrm{Y}$ is the $\mathrm{HCN}$ removal rate, the $C_{0}(\mathrm{mg} / \mathrm{m} 3)$ is the inlet concentration of $\mathrm{HCN}$, the $C_{(\mathrm{mg} / \mathrm{m} 3) \text { is the outlet }}$ concentration of HCN.

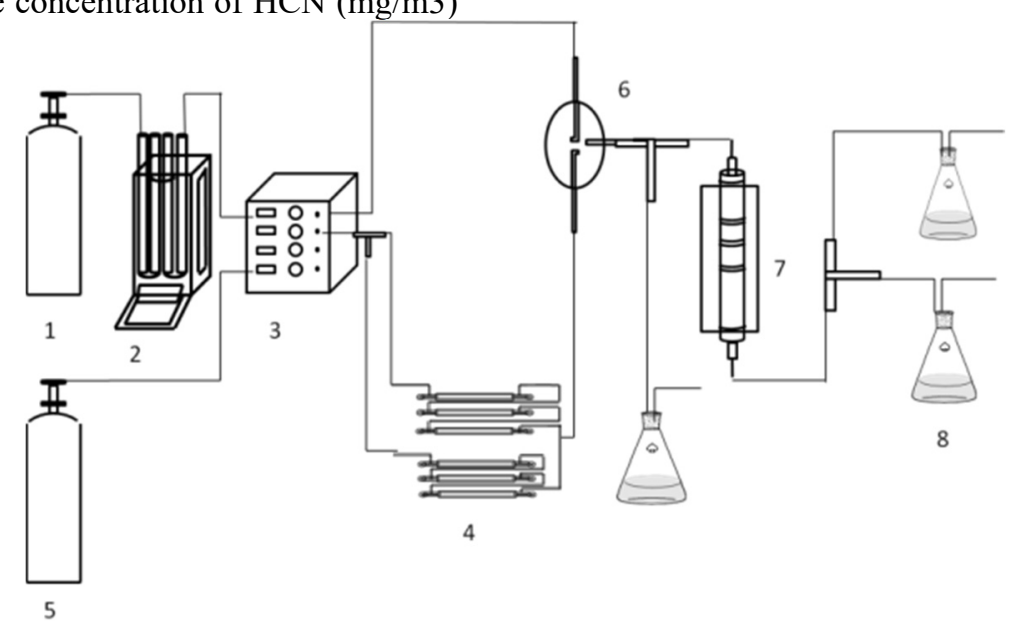

Figure 1 The device for active evaluation of catalytic materials.1. air cylinder, 2. Quadruple Scrubber 3. Mass Flow Controller, 4. Saturated Vapor Generator, 5. HCN cylinder, 6. Mixed ball, 7. Power Tube, 8. NaOH absorbent.

\section{Results and Discussion}

\subsection{The results of SEM}

SEM of $\mathrm{CeO} 2$ and catalytic materials prepared by different methods was shown in Figure 2. As presented in Figure 2(1), the $\mathrm{CeO} 2$ exhibited flowerlike mesoporous sphere with diameter of $2 \sim 3 \mu \mathrm{m}$, which proved the $\mathrm{CeO} 2$ were synthesized successfully. After loaded with $\mathrm{CuO}$ species, all samples still showed sphere structure, indicating $\mathrm{CuO}$ loaded couldn't significantly change the structure of the $\mathrm{CeO} 2$ support. From the figure 2(2) and 2(6), it can be seen that pore structure was formed by interweaved nanosheets on the surface of support, which testified $\mathrm{CuO}$ particles were uniformly dispersed on the $\mathrm{CeO} 2$ support. Figure 2(3), 2(4) and 2(5) showed there are a mass of irregular particles on the support which confirmed $\mathrm{CuO}$ was agglomerated on the support and weren' $t$ uniformly dispersed. From SEM figures, we concluded that different preparation methods of catalytic materials can influence the dispersion of active species.

EDS of catalytic materials from different preparation methods was presented in Figure 3. The actual load amount of $\mathrm{CuO}$ from all samples were obtained from EDS analysis and listed in Table 1, which demonstrated actual
$\mathrm{CuO}$ loading were around $8 \% \sim 10 \%$.

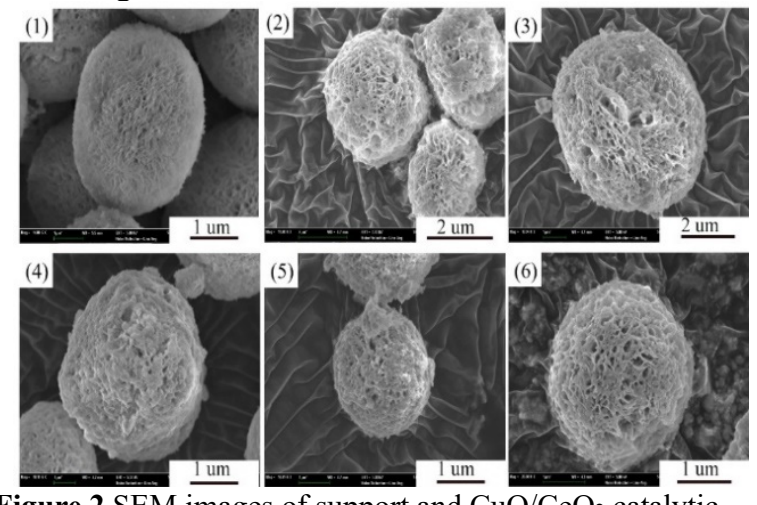

Figure $2 \mathrm{SEM}$ images of support and $\mathrm{CuO} / \mathrm{CeO}_{2}$ catalytic materials from different methods:(1) $\mathrm{CeO}_{2}$ (2) $\mathrm{Ce}-1$, (3) $\mathrm{Ce}-2$, (4) $\mathrm{Ce}-3$, , 5) $\mathrm{Ce}-4,(6) \mathrm{Ce}-5$

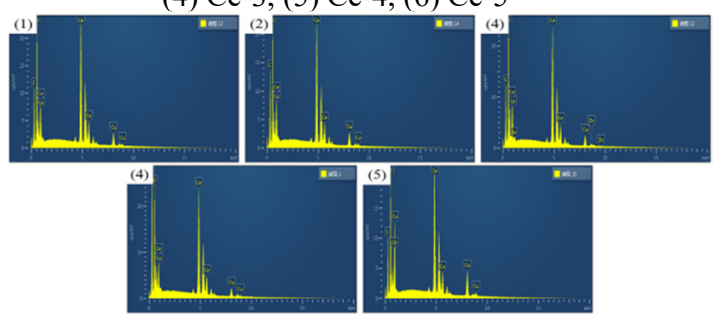

Figure $3 \mathrm{EDS}$ of $\mathrm{Cu} / \mathrm{CeO}_{2}$ catalytic material from different methods: (1) C-1, (2) C-2, (3) C-3, (4) C-4, (5) C-5 


\subsection{The results of XRD and BET}

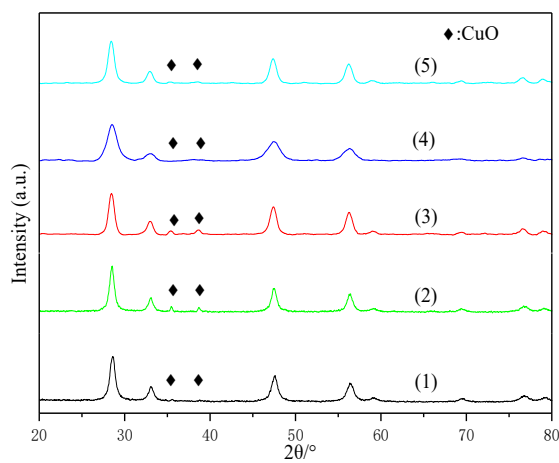

Figure $4 \mathrm{XRD}$ patterns of $\mathrm{Cu} / \mathrm{CeO}_{2}$ from different methods: (1) Ce-1, (2) Ce-2, (3) Ce-3, (4) Ce-4, (5) Ce-5

As observed in the Figure 4, all samples exhibited main reflections at $28.8^{\circ}, 33.1^{\circ}, 47.8^{\circ}, 56.5^{\circ}, 59.5^{\circ}$, $69.3^{\circ}, 77.1^{\circ}$ and $79.2^{\circ}$ in the XRD patterns corresponding to the distinct cubic fluorite diffraction pattern of $\mathrm{CeO} 2$ (JCPDS 34-0394) which implied the structure of $\mathrm{CeO} 2$ was not changed after $\mathrm{CuO}$ loaded [17], the results were consistent with SEM analysis. The distinct characteristic diffraction peaks of $\mathrm{CuO}$ were observed at 2 $\theta=35.4^{\circ}$ and $38.7^{\circ}$. According to the Scheler's formula, the crystal size of $\mathrm{CuO}$ particles were calculated and the results were listed in Table 1. It could be observed the crystal sizes of $\mathrm{Ce}-2$ and $\mathrm{Ce}-3$ were larger than others owing to the accumulation of $\mathrm{CuO}$ on the support. For Ce4 , the intensity of its diffraction peak were lower than others, and the crystal size of $\mathrm{CuO}$ particle was smallest, which might be explained the $\mathrm{CuO}$ doped into the lattice of $\mathrm{CeO} 2$, and formed the $\mathrm{Cu}-\mathrm{Ce}-\mathrm{O}$ solid solution [18]. The surface area of all samples was measured by BET. It could be observed that surface area of C-5 $(61.478 \mathrm{~m} 2 / \mathrm{g})$ was the largest. The large surface area was beneficial to increase dispersion of $\mathrm{CuO}$ on the surface of support and enhanced the interaction between $\mathrm{CuO}$ and $\mathrm{CeO} 2$ support, which limited the accumulation of $\mathrm{CuO}$.

Table 1 Actual load, surface area and crystallite size of samples

\begin{tabular}{cccc}
\hline Sample & $\begin{array}{c}\text { CuO loading } \\
(\text { wt.\%) }\end{array}$ & $\begin{array}{c}\text { Surface } \\
\text { area } /\left(\mathrm{m}^{2} / \mathrm{g}\right)\end{array}$ & $\begin{array}{c}\text { Crystallite } \\
\text { size }^{\mathrm{b}} / \mathrm{nm}\end{array}$ \\
\hline $\mathrm{Ce}-1$ & 8.63 & 60.3 & 19.4 \\
$\mathrm{Ce}-2$ & 8.57 & 57.6 & 28.2 \\
$\mathrm{Ce}-3$ & 8.10 & 58.3 & 30.3 \\
$\mathrm{Ce}-4$ & 9.34 & 50.6 & 16.3 \\
$\mathrm{Ce}-5$ & 9.28 & 61.5 & 18.3 \\
\hline
\end{tabular}

${ }^{\mathrm{a}}$ Calculated by EDS ${ }^{\mathrm{b}}$ Calculated by Scheler's formula.

[15]. According to the literature [16], the reduction peak of $\mathrm{CuO}$ were located at $350{ }^{\circ} \mathrm{C}$, however, in Figure 5, the peaks from samples all transferred to the low temperature region. It could be explained that the reductive temperature of $\mathrm{CuO}$ was related to the dispersion of $\mathrm{CuO}$ on the support. The highly dispersed $\mathrm{CuO}$ can enhance the interaction between support and active species, and decrease the reductive temperature of $\mathrm{CuO}$. It can be concluded that $\mathrm{Ce}-5$ presented the best redox properties among all samples. ascribed to the reduction of $\mathrm{Cu}+$ to $\mathrm{Cu}$. The peak of $\gamma$ came from the reduction of active oxygen species on $\mathrm{CeO} 2$

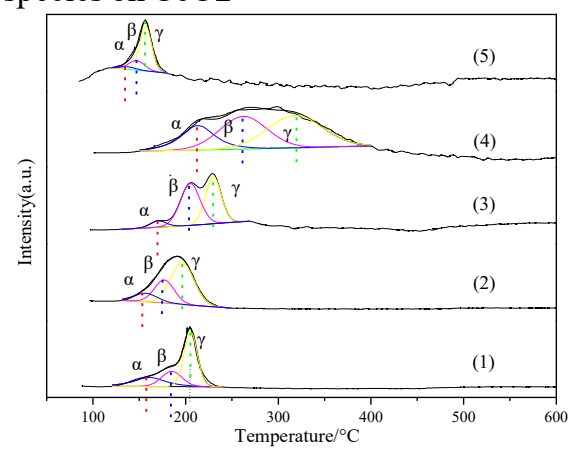

Figure $5 \mathrm{H}_{2}-\mathrm{TPR}$ of $\mathrm{Cu} / \mathrm{CeO}_{2}$ from different synthetic methods: (1) $\mathrm{Ce}-1$, (2) $\mathrm{Ce}-2$, (3) $\mathrm{Ce}-3$, (4) $\mathrm{Ce}-4$, (5) $\mathrm{Ce}-5$

\subsection{Catalytic activity}

Figure 6 showed the HCN removal performance over different samples at the condition of $30{ }^{\circ} \mathrm{C}, 61146 \mathrm{~h}-1$ and 5 vol.\% $\mathrm{H} 2 \mathrm{O}$. As presented, the catalytic activity toward $\mathrm{HCN}$ of all samples followed this order: $\mathrm{Ce}-5>\mathrm{Ce}-1>$ $\mathrm{Ce}-3>\mathrm{Ce}-2>\mathrm{Ce}-4$. The breakthrough time of $\mathrm{Ce}-4, \mathrm{Ce}-$
3 and Ce- 2 were all less $40 \mathrm{~min}$, and the C-4 showed the worst $\mathrm{HCN}$ removal activity, the removal rate of which was less than $100 \%$ after reaction for $20 \mathrm{~min}$. Among all samples, Ce-5 showed the highest catalytic activity toward $\mathrm{HCN}$, the breakthrough time of which was more than 70 min, even at $90 \mathrm{~min}$, the $\mathrm{HCN}$ removal rate over Ce-5 was still more than $95 \%$. In our previous study, the catalytic activity of $\mathrm{CeO} 2$ toward $\mathrm{HCN}$ was the lowest, the HCN 
removal rate was lower than $10 \%$ when the reaction time exceeded $80 \mathrm{~min}$. The $\mathrm{CuO}$ phase in the prepared samples played an important role in the HCN catalytic removal.

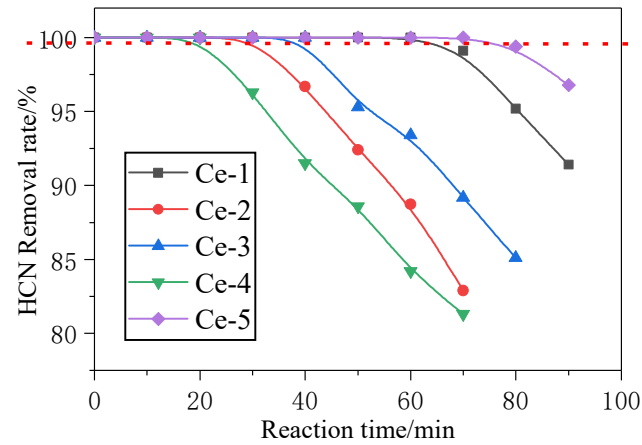

Figure $6 \mathrm{HCN}$ removal rate of $\mathrm{Cu} / \mathrm{CeO}_{2}$ from different methods at the condition of $30^{\circ} \mathrm{C}, 61146 \mathrm{~h}^{-1}, 5$ vol. $\% \mathrm{H}_{2} \mathrm{O}$

\subsection{FT-IR analysis}

Figure 6 implied that $\mathrm{Ce}-5$ exhibited the highest catalytic activity, to examine the interaction between $\mathrm{Ce}-5$ and $\mathrm{HCN}$, the FT-IR analysis of $\mathrm{Ce}-5$ before and after reaction were conducted and the results were shown in Figure 7.

The characteristic bonds at $3412.3 \mathrm{~cm}-1$ and 1650.6 $\mathrm{cm}-1$ were ascribed to the stretching vibration of $-\mathrm{OH}$ and the bending vibration of $\mathrm{H} 2 \mathrm{O}$ adsorbed [19]. The absorption band at $774.2 \mathrm{~cm}-1$ was assigned to the $\mathrm{Ce}-\mathrm{O}$ asymmetric stretch [20]. And the absorption bond at $1319.2 \mathrm{~cm}-1$ and $1108.2 \mathrm{~cm}-1$ were attributed to the stretch vibration of CO32- and stretch vibration of C-H [21].

In the spectra of $\mathrm{Ce}-5$ after reaction, a new peak corresponding to the absorbance of $\mathrm{CuCN}$ could be observed at $2142.5 \mathrm{~cm}-1$ [22], which indicated $\mathrm{CuCN}$ was generated on the surface of $\mathrm{CuO} / \mathrm{CeO} 2$ due to the chemisorption.

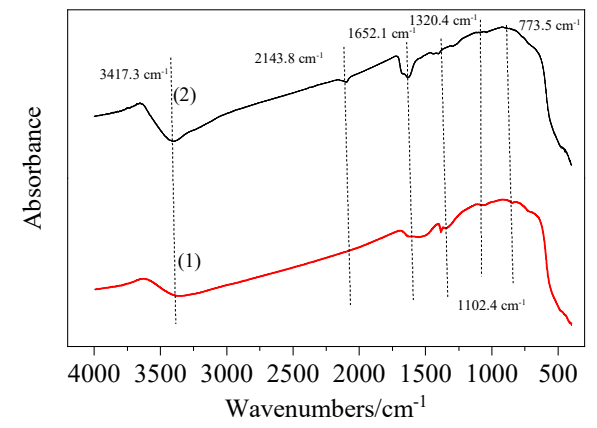

Figure 7 The FT-IR spectra of Ce-5: (1) before reaction (2) after reaction

\subsection{Discussion}

Based on above analysis, the $\mathrm{CuO}$ phase on the $\mathrm{CeO} 2$ support contributed to the high HCN removal efficiency over prepared samples, the interaction between $\mathrm{CuO}$ and $\mathrm{HCN}$ could be explained by following equation:

$$
\begin{array}{r}
2 \mathrm{CuO}+4 \mathrm{HCN} \rightarrow 2 \mathrm{CuCN}+(\mathrm{CN})_{2}+2 \mathrm{H}_{2} \mathrm{O} \\
2(\mathrm{CN})_{2}+2 \mathrm{H}_{2} \mathrm{O}+\mathrm{O}_{2} \stackrel{\mathrm{Cu}^{2+}}{\longrightarrow} 4 \mathrm{HOCN}
\end{array}
$$

Besides, the HCN could also be converted directly to HOCN with the participation of $\mathrm{O} 2$ according to the literature reported.

$$
\mathrm{HCN}+\mathrm{O}_{2} \stackrel{\mathrm{Cu}^{2+}}{\longrightarrow} \mathrm{HOCN}
$$

The reason why $\mathrm{Ce}-5$ showed the highest catalytic activity toward HCN among all samples prepared by different methods was analyzed based on the experimental results and the SEM, XRD, BET and H2-TPR characterization. The dispersion of $\mathrm{CuO}$ particles, the interaction between $\mathrm{CuO}$ and $\mathrm{CeO} 2$ support as well as redox properties all influenced the activity for $\mathrm{HCN}$ removal. The XRD results implied the $\mathrm{CuO}$ species had smaller crystal size $(18.3 \mathrm{~nm})$ due to the stronger interaction between $\mathrm{CuO}$ and $\mathrm{CeO} 2$ support. The SEM and BET analysis implied the $\mathrm{CuO}$ had high dispersion on the support. The lower reduction temperature of Ce-5 in the H2-TPR spectra showed the excellent redox properties as results of the reduction of easily reduced metal species and the stronger interaction between $\mathrm{CuO}$ and $\mathrm{CeO} 2$.

\section{Conclusion}

Experimental results indicated the catalytic activity of samples were influenced greatly by the preparation methods, among all methods, the precipitation method was proved to be suitable for preparing catalytic materials with high activity. The breakthrough time of $\mathrm{HCN}$ over $\mathrm{Ce}-5$ was more than $70 \mathrm{~min}$ at the condition of $30{ }^{\circ} \mathrm{C}, 61146 \mathrm{~h}$ 1 and $5 \mathrm{vol} \% \mathrm{H} 2 \mathrm{O}$. Combined with the results of SEM, XRD, BET and H2-TPR, the HCN removal performance of catalytic materials was closely related to the dispersion of $\mathrm{CuO}$ species on the support, the interaction between $\mathrm{CuO}$ species and support as well as redox properties.

\section{Acknowledge}

This work was supported by the Chinese Civil Air Defense Office ([2014] No.251-61).

\section{Rererences}

[1] Baum, M. M., Moss, J. A., Pastel, S. H., et al. (2007) Hydrogen cyanide exhaust emissions from in-use motor vehicles. J. Environmental ence \& Technology, 41(3): 857-62.

[2] Marrs, T. C., Maynard, R. L., Sidell, F. R., et al. (1997) Book review: Chemical Warfare Agents Toxicology and Treatment. J. Appl. Toxicol, 17: 93-93.

[3] Bright, J., Marrs, T. C., et al. (1984) Toxicity of inhaled HCN. J. Hum Exp Toxicol, 3: 521-222.

[4] Tan, H. Z., Wang, X. B., Wang, C. L., et al. (2009) Characteristics of $\mathrm{HCN}$ Removal Using $\mathrm{CaO}$ at High Temperatures. J. Energy \& Fuels, 23: 1545-1550.

[5] Zhang, Z., Drzewiecki, G.J., Hom, J. T., et al. (1994) Human cortical neuronal ( $\mathrm{HCN})$ cell lines: a model for amyloid beta neurotoxicity. J. Neuroscience Letters, 177(1-2): 162.

[6] Wang, B. B., Sheng, H. B., Shi, Y. Q., et al. (2016) The influence of zinc hydroxy stannate on reducing toxic 
gases $\left(\mathrm{CO}, \mathrm{NO}_{\mathrm{x}}\right.$ and $\left.\mathrm{HCN}\right)$ generation and fire hazards of thermoplastic polyurethane composites. J. Journal of Hazardous Materials, 314: 260-269.

[7] Li, Y. J., Yang, H., Zhang, Y. H., et al. (2018) Catalytic decomposition of $\mathrm{HCN}$ on copper manganese oxide at low temperatures: Performance and mechanism. J. Chemical Engineering Journal. 346: 621-629.

[8] Ning, P., Qiu, J., Wang, X. Q., et al. Metal loaded zeolite adsorbents for hydrogen cyanide removal. J. Journal of Environmental ences, 04: 808-814.

[9] Kr?Cher, O., Elsener, M. (2009) Hydrolysis and oxidation of gaseous $\mathrm{HCN}$ over heterogeneous catalysts. J. Applied Catalysis B Environmental, 92(12): $75-89$.

[10] Wang, Q., Wang, X. Q., Wang, L., L., et al. (2019) Catalytic oxidation and hydrolysis of $\mathrm{HCN}$ over $\mathrm{La}_{\mathrm{x}} \mathrm{Cu}_{\mathrm{y}} / \mathrm{TiO}_{2}$ catalysts at low temperatures. J. Microporous \& Mesoporous Materials, 282: 260-268.

[11] Ma, Y. X., Wang, X.Q., Ning, P., et al. (2017) Effects of structures and surface species over Al-Ti-Ox catalysts on removal of HCN. J. Journal of the Taiwan Institute of Chemical Engineers, 1-9.

[12] Hu, Y.N., Liu, J. P., Cheng, J. H., et al. (2017) Coupling catalytic hydrolysis and oxidation of $\mathrm{HCN}$ over HZSM- 5 modified by metal $(\mathrm{Fe}, \mathrm{Cu})$ oxides. J. Applied Surface Science, 427: 843-850.

[13] Chen, F., Chen, Z.G., Li X.Z., et al. (2011) Synthesis of $\mathrm{CeO}_{2}$ Hollow Nanosphere Using Carbon Sphere as Template. J. Journal of the Chinese Ceramic Society, 39(3): 397-402(6).

[14] Huang, P. X., Wu, F., Zhu B. L., et al. (2005) $\mathrm{CeO}_{2}$ nanorods and gold nanocrystals supported on $\mathrm{CeO}_{2}$ nanorods as catalyst. J. Journal of Physical Chemistry B, 109(41): 19169-74.

[15] Sun, C. W., Sun, J., Xiao, G. L., et al. (2006) Mesoscale Organization of Nearly Monodisperse Flowerlike Ceria Microspheres. J. Phys. Chem. B, 110: 13445-13452.

[16] Tan, L., Qiao, T., Gao, H.Y., et al. (2016) Preparation and catalytic performance of mesoporous ceria-base composites $\mathrm{CuO} / \mathrm{CeO}_{2}, \mathrm{Fe}_{2} \mathrm{O}_{3} / \mathrm{CeO}_{2}$ and $\mathrm{La}_{2} \mathrm{O}_{3} / \mathrm{CeO}_{2}$. J. Journal of Porous Materials.

[17] She, Y., Zheng, Q., Li, L., et al. (2009) Rare earth oxide modified $\mathrm{CuO} / \mathrm{CeO}_{2}$ catalysts for the water-gas shift reaction. J. International Journal of Hydrogen Energy, 34(21): 8929-8936.

[18] Yao, X., Chen, L., Kong, T., et al. (2017) Support effect of the supported ceria-based catalysts during $\mathrm{NH}_{3}$-SCR reaction. J. Chinese Journal of Catalysis, 38(8): 1423-1430.

[19] Tan, K., Zuluaga, S., Gong, Q., et al. (2015) Competitive co-adsorption of $\mathrm{CO}_{2}$ with $\mathrm{H}_{2} \mathrm{O}, \mathrm{NH}_{3}$, $\mathrm{SO}_{2}, \mathrm{NO}, \mathrm{NO}_{2}, \mathrm{~N}_{2}, \mathrm{O}_{2}$, and $\mathrm{CH}_{4}$ in M-MOF-74 (M= $\mathrm{Mg}, \mathrm{Co}, \mathrm{Ni})$ : the role of hydrogen bonding. J. Chemistry of Materials, 27(6): 150216154516004.

[20] Li, X.P., Zhao, R. X., Jiang H., et al. (2016) Preparation and Catalytic Properties of $\mathrm{ZnO}-\mathrm{CeO}_{2}-$
$\mathrm{TiO}_{2}$ Composite. J. Synthesis and Reactivity in Inorganic and Metal-Organic Chemistry, 46(5): 775782.

[21] Bazin, P., Saur, O., Lavalley, J. C., et al. FT-IR study of $\mathrm{CO}$ adsorption on $\mathrm{Pt} / \mathrm{CeO} 2$ : characterisation and structural rearrangement of small $\mathrm{Pt}$ particles[J]. Physical Chemistry Chemical Physics, 2004, 7: 187194.

[22] Zhang, J.J., Yin, Q. G., Zhao, R. L., (1990). EX-IR reflection-absorption studies for the film on copper electrode. J. Journal of Central China Normal University (Natural Sciences). 